\title{
The 'Prioritizing Safety for Sex Workers Policy': A sex worker rights and anti-trafficking initiative
}

\author{
Alexandra Lutnick
}

\begin{abstract}
This article presents a case study of how sex worker and anti-trafficking organisations and activists in San Francisco, California, worked together to develop and pass the 'Prioritizing Safety for Sex Workers Policy'. This policy, as enacted by the San Francisco District Attorney's Office and the San Francisco Police Department, creates a legal environment where people can come forward and report to law enforcement when they are a victim of or witness to an array of violent crimes while engaged in sex work, and not be arrested or prosecuted for their involvement in that criminalised behaviour or for any misdemeanour drug offences. The article details how the groups came together and the challenges they faced while developing the policy. The work was fuelled by the recognition that no one wants people in the sex industry to experience violence. That is true whether selling sex is their choice, influenced by their life circumstances, or something they are being forced or coerced to do. The Prioritizing Safety for Sex Workers Policy is a unique example of the way in which sex workers, people who have experienced trafficking, service providers, activists, women's rights policymakers, the police department, and the District Attorney's office came together around a common goal.
\end{abstract}

Keywords: sex work, human trafficking, policy, coalitions, violence, crime victim

Suggested citation: A Lutnick, "The "Prioritizing Safety for Sex Workers Policy": A sex worker rights and anti-trafficking initiative', Anti-Trafficking Review, issue 12, 2019, pp. 140-154, www.antitraffickingreview.org 


\section{Introduction}

This article is a case study of how sex worker organisations and activists worked with anti-trafficking organisations to create the 'Prioritizing Safety for Sex Workers Policy' in San Francisco, California. Issued as a policy by the San Francisco District Attorney's Office, ${ }^{1}$ and as a Department Bulletin ${ }^{2}$ by the San Francisco Police Department, ${ }^{3}$ this complementary policy creates a legal environment where people can come forward and report to law enforcement when they are a victim of or witness to violent crime while engaged in sex work, and not be arrested or prosecuted for their involvement in that criminalised behaviour or for any misdemeanour drug offences. The policy broadly defines violent crime to include sexual assault, human trafficking, stalking, robbery, assault, kidnapping, threats, blackmail, extortion, burglary, and others. It also holds police officers accountable if and/or when they are the ones perpetrating physical or sexual violence against sex workers, and defines officer misconduct against sex workers to include retaliation, coercion, or coercive intimate acts. The policy applies to youth and adults engaged in sex work, to those who are choosing to do sex work, those who are doing it because of life circumstances, and those whose experiences are characterised as trafficking. Information gathered from a victim or witness of a violent crime who is engaged in sex work, or other forms of sex trade, will not be used in any manner to investigate and prosecute that person during the course of the investigation or in the future.

The material for this case study was collected through my role as a participant in the group working on this effort. Since the early 2000s, I have been involved in sex worker rights activism in San Francisco, including addressing exploitation of adults and youth engaged in sex work and providing direct services to these communities. Some of those people identify as sex workers, some as victims and/or survivors of trafficking, and yet others-with all these terms or none of them. I also have my own lived experience of engaging in sex work and, since 2004, I have been conducting research focused on the experiences of people involved in sex trades. Much of the data we used to justify the need for

1 G Gascón, Prioritizing Safety for Sex Workers, Office of the District Attorney, City and County of San Francisco, 2017, https://sfgov.org/dosw/sites/default/files/ DA $\% 20$ Prioritizing $\% 20$ Safety $\% 20$ for $\% 20$ Sex $\% 20$ worker $\% 20$ Policy.pdf.

2 A Department Bulletin is a type of policy within the San Francisco Police Department that is issued by the Chief of Police.

3 W Scott, Prioritizing Safety for Sex Workers, Department Bulletin, 2017, https:// sfgov.org/dosw/sites/default/files/department $\% 20$ bulletin\%2017-249.pdf. 
the 'Prioritizing Safety for Sex Workers Policy' was from studies I have participated in over the years. ${ }^{4}$

\section{Sex Workers' Rights in San Francisco}

Sex workers in San Francisco have a long history of being involved in local politics. In fact, the term 'sex work' was coined in San Francisco by Carol Leigh in the late $1970 \mathrm{~s} .{ }^{5}$ Even prior to the creation of the term, there was significant organising around the rights of people in the sex trade in the city. In 1972, Margo St. James founded the group Whores, Housewives, and Others (WHO), which led to the establishment of Call Off Your Old Tired Ethics (COYOTE) in 1973. COYOTE was established to provide services to prostitutes, to increase awareness about the abuses people working in the sex industry experience, and to educate people that selling sex is legitimate work that would benefit from occupational health and safety standards. ${ }^{6}$ St. James also engaged in national and international advocacy by cofounding the National Task Force on Prostitution in 1979 as well as the International Committee for Prostitutes' Rights in 1985. ${ }^{7}$ Another key group is the US PROStitutes Collective founded in 1982. US PROS, a multiracial network of current and former sex workers, campaigns for the decriminalisation of sex work and for justice, protection, and resources so that no one is forced into prostitution through poverty.

4 See D Cohan et al., 'Sex Worker Health: San Francisco style', Sexually Transmitted Infections, vol. 82, no. 5, 2006, pp. 418-422, https://doi.org/10.1136/ sti.2006.020628; A Lutnick, Domestic Minor Sex Trafficking: Beyond victims and villains, Columbia University Press, New York, 2016; A Lutnick and D Cohan, 'Criminalization, Legalization or Decriminalization of Sex Work: What female sex workers in San Francisco, USA say', Reproductive Health Matters, vol. 17, no. 34, 2009, pp. 38-46, https://doi.org/10.1016/S0968-8080(09)34469-9; A Lutnick and M Kandel, Engaging Unheard Communities: Finding common ground to address violence against sex workers, Presented at the 2016 Statewide Domestic Violence Conference, Shifting the Lens: Transforming our approach to domestic violence, Berkeley, CA; A Lutnick et al., 'Examining the Associations between Sex Trade Involvement, Rape and Symptomatology of Sexual Abuse Trauma', Journal of Interpersonal Violence, vol. 30, no. 11, 2015, pp. 1847-1863, https:// doi.org/10.1177/0886260514549051.

5 C Leigh, 'Inventing sex work', in J Nagel (ed.), Whores and Other Feminists, Routledge, New York, 1997, pp. 226-231.

6 A Lutnick, 'COYOTE', in M H Ditmore (ed.), Encyclopedia of the History of Prostitution, Greenwood Publishing Group, Santa Barbara, CA, 2006.

7 A Lutnick, 'Margo St. James', in M H Ditmore (ed.), Encyclopedia of the History of Prostitution, Greenwood Publishing Group, Santa Barbara, CA, 2006. 
Sex worker advocacy and political engagement continued in the 1990s. The Exotic Dancers' Alliance (EDA) was founded in 1993. EDA's work focused on labour organising in adult entertainment theatres, including helping individuals receive redress from adult entertainment theatres, and providing one-on-one and group consults. ${ }^{8}$ In 1993, the San Francisco Board of Supervisors called for the establishment of a Task Force on Prostitution. The Task Force was charged with investigating prostitution in the city, surveying social and legal responses, as well as making recommendations about social and legal reforms which would best respond to San Francisco's needs while using city resources more efficiently. After meeting for eighteen months, the Task Force issued its final report in 1996. The Task Force determined that the city's responses to prostitution were ineffective and harmful. The report noted that sex workers were afraid to call the police when they were victims of crime for fear of arrest. Responding to the harms of criminalisation and the fact that, if someone had an arrest record, it was extremely difficult for them to find legal employment, the Task Force recommended that San Francisco decriminalise prostitution and funnel the money that would be spent on enforcement into services for 'needy constituencies'.?

Around the same time, in the early 1990s, the anti-trafficking, prostitution abolitionist organisation, the Standing Against Global Exploitation (SAGE) Project, Inc., was founded by the late Norma Hotaling. Ms Hotaling described herself as a survivor of commercial sexual exploitation and heroin addiction, and sought to end the commercial sex industry. As an organisation, SAGE felt strongly about referring to involvement in the sex industry as 'human trafficking', and not 'prostitution' or 'sex work'. ${ }^{10}$ Initially, the organisation referred to people involved in sex work as 'prostituted women' and, over time, began using the term 'trafficking victims or survivors'. SAGE's work included the creation of the 'First Offender Prostitution Program (FOPP)', also referred to as the 'John School.' 'This programme was created in collaboration with the San Francisco Police Department (SFPD) and the San Francisco District Attorney's (SFDA) Office. FOPP's intent was to target men soliciting sex and divert non-violent, first time offenders to a daylong education programme in hopes that they would not reoffend. This 'end demand'oriented programme has been replicated throughout the United States despite

8 A Lutnick, 'The St. James Infirmary: A history', Sexuality and Culture, vol. 10, issue 2, 2006, pp. 56-75, https://doi.org/10.1007/s12119-006-1015-3.

9 Board of Supervisors of the City and County of San Francisco, San Francisco Task Force on Prostitution: Final Report, 1996, https://archive.org/details/ sanfranciscotask19sanf/page/n3.

10 Lutnick, 2016. 
findings that it lacked an evidence-based curriculum, did not meet the National Institute of Justice's criteria of programmes to reduce recidivism, did not result in lower self-report scores about the likelihood of soliciting in the future, and the costs of the programme exceeded the fee revenues. ${ }^{11}$

Two key events occurred in 1999. Nearly three decades after the establishment of COYOTE, and three years after the publication of the Task Force on Prostitution's final report, the St. James Infirmary (SJI) was founded in San Francisco. SJI is the nation's first and only peer-led occupational safety and health clinic for former and current sex workers of all genders, and their family members. SJI was founded by COYOTE, EDA, and the San Francisco Department of Public Health, specifically the STD Prevention and Control Department. ${ }^{12}$ Also in 1999, US PROS organised a public hearing at City Hall at which many sex workers testified and which led to a historic Board of Supervisors resolution, titled 'Mitigating Violence against Prostitutes'. The work of both SJI and US PROS continues. More recently, in 2013, US PROS spearheaded a state-wide campaign and won the repeal of a discriminatory regulation which had excluded sex workers from state compensation for rape and other violence.

\section{Catalyst for a New Policy}

In recent years, as the sex industry has come under greater scrutiny and suppression as a result of anti-trafficking policies, sex worker rights organisations and activists have maintained a seat at the table in San Francisco. February 2014 brought the unlikely start of a collective effort of sex worker and anti-trafficking organisations and activists working towards developing the 'Prioritizing Safety for Sex Workers Policy', when sex worker rights activists protested an end demand event held at the San Francisco Public Library. An organiser for the event mentioned to someone that they did not realise was a sex worker that they might be interested in the event because it would include a presentation by a researcher. The organiser went on to say that they did not want sex workers to attend because they felt they would be disruptive. That sex worker understandably told other sex worker community members about the event and suggested that they could have the greatest impact if they showed up with tape on their mouths and designated only a few people to make

${ }^{11}$ M Shively, et al., Final Report of the Evaluation of the First Offender Prostitution Program, Office of Research and Evaluation, National Institute of Justice, Washington, DC, 2008; San Francisco Budget Analyst, Management Audit of the San Francisco First Offender Prostitution Program, Board of Supervisors of the City and County of San Francisco, 2009.

12 A Lutnick, 'The St. James Infirmary: A history'. 
comments. Members of the Sex Worker Outreach Project (SWOP) and Bay Area Sex Worker Advocacy Network (BAYSWAN) organised the protest. The protest had the intended effect and led the San Francisco Department on the Status of Women (DOSW), the group that staffs the San Francisco Mayor's Task Force on Anti-Human Trafficking, to recognise the importance of including sex workers in conversations about anti-trafficking efforts. They realised that, when advocates and legislators claim that abolishing the sex industry will eliminate human trafficking, there will be collateral consequences for all people who are selling sex, regardless of whether it is by choice, circumstances, or coercion.

While the DOSW and sex worker organisations began meeting, it was announced in March 2014 that San Francisco County had become one of the first of five counties in the US to receive funding from Demand Abolition's Cities Empowered Against Sexual Exploitation (CEASE) programme. Under the umbrella of Swanee Hunt's non-profit, Hunt Alternatives, Demand Abolition's strategy was, and continues to be, to fund a collaborative group of law enforcement officials and social service providers that would focus on reducing the number of people buying sex by about 20 per cent. The ideology behind Demand Abolition's work is that commercial sex is inherently harmful to all involved, and by targeting the 'demand' side, they hope to see the sex industry eradicated. As part of the CEASE Network, counties receiving funding are expected to launch public media campaigns communicating Demand Abolition's philosophy.

In San Francisco, the collaborative group that received the funding from the CEASE Program was the DOSW, SAGE, the San Francisco District Attorney's Office (SFDA), and the San Francisco Police Department (SFPD). After receiving the funding, the coordinator for CEASE's work in the city began meeting with all key community groups and representatives, including sex workers. It was important that the DOSW was already meeting with sex worker groups because it made it much easier to link the coordinator to key community members and organisations. Sex worker and non-sex worker organisations and activists alike shared the concern that end demand approaches to the sex industry always bring collateral consequences. Those formative meetings involved sex worker rights activists, survivors of trafficking, and organisations working with sex workers, LGBTQ youth, and people experiencing trafficking. ${ }^{13}$ Conversations focused on the dangers people would face when

13 It needs to be noted that these groups are not mutually exclusive. For example, an LGBTQ youth organisation is likely also to be working with people involved in sex work, and young people who identify their experiences as trafficking. Similarly, sex worker organisations also provide services to people who are experiencing trafficking. 
20 per cent of their client base was eliminated and not replaced by viable alternatives. The groups also shared their concerns about other safety consequences when clients are targeted. These included the reality that such a strategy often pushes the sex trades even further out of sight, with clients wanting to rush negotiations and screening, and forces the person selling sex into more isolated areas, all in an attempt to avoid law enforcement detection. All of these factors resulted in people selling sex experiencing increased rates of violence and abuse. Although San Francisco County was awarded USD 80,000 to participate in the national initiative that eventually became CEASE, after these conversations, the San Francisco collaborative group withdrew from the grant and gave the money back. ${ }^{14}$ This decision was also influenced by Demand Abolition's requirement that grant recipients pledge that the sex industry is inherently harmful. Minouche Kandel of the DOSW shared that, 'We are trying to be very clear that there's a distinction between sex work engagement by adults and sex trafficking. ... We were trying to be nuanced in how we approach this'. ${ }^{15}$

While exploring areas of shared goals during the following meetings, the group recognised that we were all united in wanting to reduce the violence experienced by people who sell sex. Whether someone's involvement in sex work is because of choice, circumstances, or coercion, they are unfortunately targets of perpetrators who know that, because prostitution is criminalised, their victims are much less likely to report the crime. Similarly, people experiencing trafficking in the sex industry are told by those exploiting them that the police will not believe them, and instead they will be arrested because they are engaged in criminalised activities. With a common goal identified, the group began to discuss how best to reduce violence against sex workers and invited more agencies to participate in the meetings.

Many groups were involved in the work on the Safety Policy. These included sex worker rights activists, survivors of trafficking, community-based researchers, legal rights and human rights organisations, as well as organisations working with sex workers, LGBTQ youth, people experiencing trafficking, and other members of the Sex Work and Trafficking Policy Impact Committee

\footnotetext{
${ }^{14}$ S Levin, 'Oakland City Council takes stand against sex workers', East Bay Express, 4 November 2015, retrieved 7 January 2019, https://www.eastbayexpress.com/ oakland/oakland-city-council-takes-stand-against-sex-workers/ Content?oid $=4563294$.

15 Ibid.
} 
of the Mayor's Task Force on Anti-Human Trafficking. ${ }^{16}$ The main purpose of the committee was to flag how trafficking policies might negatively impact sex workers and other vulnerable community members. Figuring out the relationship of the working group (those agencies working on the policy) to the Mayor's Task Force on Anti-Human Trafficking, and even naming the committee proved challenging. The group ruminated on the committee name for over a year. The Department on the Status of Women does not state an official position on either decriminalisation or abolition of sex work. As such, it was not willing to coordinate a committee which included 'Sex Worker Rights' in the name. Some members thought that having a sex worker-focused committee as an official part of a human trafficking task force created unique opportunities to centre sex workers' voices at a table from which they are generally excluded. Given the prior negative experiences with trafficking initiatives that caused harm to sex workers, others were concerned about the implications of being associated with an anti-trafficking task force. Ultimately, members agreed that the working group would function as a committee of the larger task force and that participating agencies and individuals did not have to become formal members of the task force.

The groups working on the project had been providing direct services to and conducting research with sex workers, people experiencing exploitation in the sex industry, and youth involved in the sex trades. Consequently, we were able to pull from our work to help inform our efforts. Likewise, many of us also had lived experiences selling sex. Both the personal and professional knowledge we collectively shared was crucial to getting the Safety Policy developed and authorised. Although historically SAGE has objected to the term 'sex work', after the death of its founder, subsequent executive directors were more open to finding common ground and engaged in meetings with sex worker organisations, such as St. James Infirmary, to explore harm reduction initiatives they could collaboratively address. SAGE closed in the fall of 2014, so its involvement in the policy's development did not continue through to its enactment. Although agencies definitely exist in San Francisco that would be opposed to the terms sex work or sex workers, those groups were not part of this process.

16 The key organisations and individuals included Asian Pacific Islander Legal Outreach, Bay Area Sex Worker Advocacy Network (BAYSWAN), the Department on the Status of Women (DOSW), the Human Rights Commission, LYRIC, the Public Defender's Office, San Francisco Women Against Rape (SFWAR), Sex Workers Outreach Project (SWOP), Standing Against Global Exploitation (SAGE), St. James Infirmary (SJI), US PROStitutes Collective, and researcher alexandra lutnick. 


\section{Evidence of the Need for the Policy}

At the first meeting with the SFPD and SFDA in August 2014, working group members came prepared with data reflecting over ten years of research done in San Francisco on the experiences of people who sell sex. We shared findings that showed the unfortunate reality that people involved in sex work face high rates of violence from a variety of sources. For example, St. James Infirmary's intake data showed that among 783 sex workers, 36 per cent reported sex work-related violence, with trans women at significantly higher risk of work violence, including violence perpetrated by customers and police officers. ${ }^{17} \mathrm{~A}$ study conducted by SJI and the University of California, San Francisco found that among 247 cisgender women involved in sex work, 32 per cent reported physical attack and 29 per cent reported sexual assault while doing sex work. That study also examined experiences with police officers and found that 14 per cent of the women reported having been threatened with arrest unless they had sex with a police officer, 21 per cent had police officers pay them for sex, 2 per cent had been arrested after having sex with a police officer, and 36 per cent reported verbal, emotional, physical, or sexual abuse by law enforcement. ${ }^{18}$ Qualitative interviews conducted for that study revealed the women's perceptions of and experiences with the police. One woman shared her perspective on what would happen if she went to the police for help: 'When you're prostituting and something happens to you, the police don't really want to help you. Because you're already committing a crime to them. So it is like why should they help the criminal?' Another woman described what occurred the first time she was arrested:

The first arrest really sucked. I was young. I just wasn't really bright at 20. I didn't know much about my rights or if I could fight back. A female cop and two other cops came into my tiny studio apartment with the guy that came in as a supposed date. He totally felt me up. It was insane. And then he called me some names. So I thought that kind of sucked too. But I really didn't know, like I really thought that he had the right to feel me up. You were doing something wrong so he had the right to squeeze you and stick his finger up there. Because you were doing something wrong. ${ }^{19}$

A study conducted by RTI International found that among 322 cisgender women who use methamphetamine, 61 per cent had traded sex in the past six months. Of those women, 77 per cent had been raped as adults, and 49 per cent reported physical assault in the past six months (most often inflicted by

17 D Cohan et al.

18 Lutnick and Cohan.

19 Lutnick and Kandel. 
acquaintances and clients). In that study, women who traded sex were 1.9 times more likely to be physically assaulted by people other than intimate partners, and 2.7 times more likely to be raped by people other than intimate partners. ${ }^{20}$ We also shared the findings from research that focused on young people (under the age of 18) who trade sex. In that study, interviews with case managers in San Francisco, Chicago, and New York City revealed that young people reported that they had been physically and sexually assaulted by police. A case manager in San Francisco shared the story about how, during a prostitution bust, a police officer sexually abused her client:

[S] he got in his car and he said that he didn't have money and that they were going to drive to the gas station for him to be able to use an ATM, get some gas and get some money. And one of the things that she said was that he let her fondle him on the entire drive. She said it was at least a solid five minutes and she, one of the things she asked me, she said, "I don't understand, if he's an undercover cop and I'm a minor, isn't he not supposed to," you know, "let me do that?"...[T] hat's something that I do hear commonly, is that the officers seem to take definite advantage and become yet another exploiter. $^{21}$

These research findings, coupled with input from direct service providers and people with lived experience, helped the SFPD and SFDA better understand that most sex workers, and people experiencing exploitation in the sex industry, do not go to the police when they have been victimised. The policy we were asking for would be the first step towards creating a social and legal environment where people can seek help when they are victims or witnesses of violence.

At one of the meetings, representatives from the police department asked what it would take to build trust with the sex worker community. The group's response was that the first step would be to stop arresting us. Although many in the group would prefer full decriminalisation, we felt an immediate and achievable goal would be to end the criminalisation of sex workers who are victims of violent crimes. Both the SFDA and SFPD expressed concerns about the prevalence of violence being perpetrated against sex workers in San Francisco and saw the proposed policy as an effort towards curbing violence by ensuring that victims feel safe to report crimes, regardless of their involvement in the sex industry. They recognised that sex workers and people exploited in sex work are subject to violence and sexual assault, and when many of these crimes go unreported, law enforcement investigators are unable to hold

20 Lutnick et al.

${ }^{21}$ Lutnick, 2016, p. 40. 
perpetrators accountable. Similarly, the two departments understood that, in San Francisco, a sanctuary city, when individuals do not report violent crimes for fear of arrest, deportation, or prosecution, the entire community suffers. Although both departments recognised the need for the proposed policy, getting the policy enacted proved more challenging than we anticipated during these early meetings.

\section{Enacting the Policy}

For the 'Prioritizing Safety for Sex Workers Policy' to include protection from both arrest and prosecution, the SFDA and SFPD would each need to write their own policies. This is because neither group has the authority to develop and implement policies for the other. The SFDA's Office was immediately on board, worked with our group to draft the language of the policy, and enacted it within six months. Its policy states that, if a sex worker is a victim of a violent crime, they will not face charges for prostitution or minor drug offences. ${ }^{22}$

Obtaining the support of the San Francisco Police Department was considerably more challenging. It took almost three years for the SFPD to finalise and enact its Bulletin. In part, this was a result of key staff turnover in the department. Each time the captain of the Special Victims Unit changed, or the chief of the SFPD changed, we had to start all over again. We would reintroduce the research findings, share the draft language, and then wait for things to start moving again. The meetings with SFPD representatives also created additional tensions. During one meeting, when a community member asked what the difference was between assault and battery, a lieutenant demonstrated what battery was by grabbing a staff member from one of the non-profits present without warning or permission.

We also experienced significant pushback from the SFPD because we wanted language included about holding law enforcement officers accountable if they were the ones who perpetrated violence. The police agreed to sign the policy if we removed the clause that read:

Violence, harassment, coercion or retaliation committed by any law enforcement officer against sex workers is not tolerated and will be investigated, which may result in disciplinary or criminal action. During the course of an investigation or potential arrest, law enforcement may not engage in any type of sexual act with a sex worker.

22 Gascón. 
For our group, this clause was non-negotiable. We threatened to take the policy to the San Francisco Board of Supervisors because they would have the authority to enact it. We also attended a Police Commission hearing to voice our complaints and went to the press about the challenges we were experiencing trying to get the policy passed. ${ }^{23}$

Fortunately, in December 2017, the SFPD released the Prioritizing Safety for Sex Workers Bulletin ${ }^{24}$ complete with the language holding law enforcement officers accountable if they are the perpetrators of violence. We were now able to go public with the two policies. The SFDA's policy is active indefinitely. The SFPD Bulletin is active for three years and will then be up for renewal. Efforts are underway to develop the required training programme for the SFPD on sex work and crimes against sex workers. This training is being developed by agencies that work with sex workers and people experiencing exploitation in the sex industry. Outreach to sex worker communities is currently underway to ensure that people know about this resource.

\section{Discussion}

Some level of interaction with law enforcement is needed to benefit from the 'Prioritizing Safety for Sex Workers Policy'. The group of service providers, activists, and people with lived experiences who helped develop the policy know that this is a key limitation. A significant amount of research highlights the ways in which police are sometimes the most frequent perpetrators of violence against sex workers, ${ }^{25}$ with some viewing the police as just another occupational hazard. ${ }^{26}$ Most crimes against sex workers go unpunished, as

23 J O Lamb, 'SFPD and Sex-worker Advocates at Odds Over Sanctuary-like Policy', San Francisco Examiner, 19 July 2017, retrieved 7 January 2019, http:// www.sfexaminer.com/sfpd-sex-worker-advocates-odds-sanctuary-like-policy/.

${ }^{24}$ Scott.

25 J Hay, 'Police Abuse of Prostitutes in San Francisco', Gauntlet Magazine, vol. 1, no. 7, 1994; F Gragg et al., New York Prevalence Study of Commercially Sexually Exploited Children, WESTAT, Rockville, Md., 2007; J Iman et al., Girls Do What They Have to Do to Survive: Illuminating methods used by girls in the sex trade and street economy to fight back and Heal, Young Women's Empowerment Project, Chicago, 2009; Lutnick, 2016; S Simon and R Thomas, Eight Working Papers/Case Studies: Examining the intersections of sex work law, policy, rights and health, Sexual Health and Rights Project, Open Society Institute, New York, 2006; J Thukral and M Ditmore, Revolving Door: An analysis of street-based prostitution in New York City, Urban Justice Center, Sex Workers Project, New York, 2003; CA Torres and N Paz, Bad Encounter Line: A participatory action research project, Young Women's Empowerment Project, Chicago, 2012.

26 Hay. 
most sex workers do not go to the police when they have been victimised. ${ }^{27}$ This begs the question of why we would create a policy that positions law enforcement as the first responders.

Many of the groups working on the policy believe that an anti-criminalisation framework is what would truly address the rights and safety of people involved in sex work. Recognising that the decriminalisation of prostitution would take (and has taken) longer to achieve than the Safety Policy, we felt that the policy could be a small but important harm reduction initiative. Not all groups involved in developing and implementing the policy would advocate for the decriminalisation of sex work. This is where addressing the shared concern about violence was used strategically to create a policy that will hopefully mitigate some of the harms people engaged in sex work experience. Not all sex workers want to involve the police when they are victims or witnesses of violent crimes. Some, however, do. For those who do, this policy will hopefully facilitate a process that allows them to seek the legal recourses they desire. Likewise, for some in the community, and all those working on the policy, it was hugely important and considered a win that the SFPD Bulletin explicitly stated that law enforcement officers will be held accountable if they are the perpetrators of violence against sex workers.

An aspect that is likely unique to San Francisco is that the groups working on the policy had no concerns about using the term sex work, but many of the sex worker organisations and activists struggled with the anti-trafficking framework that was included. In part, this was because most of those people do not use the language of trafficking to speak about abuses and exploitation that sex workers experience and know that limiting the discussion only to the violence people may experience reifies the rhetoric of victimhood. It can also be attributed to the reality that many anti-trafficking initiatives and policies have resulted in severe collateral consequences for people engaged in sex work. Those who struggled with this ultimately decided that they wanted to take advantage of this collaborative opportunity to try to make changes from the inside, while still pushing for a framework that affirms the human rights of people involved in sex work.

${ }^{27}$ K Shannon, T Kerr, and S Allinott, 'Social and Structural Violence and Power Relations in Mitigating HIV Risk of Drug-using Women in Survival Sex Work', Social Science \& Medicine, vol. 66, no. 4, 2008, pp. 911-921, https://doi.org/ 10.1016/j.socscimed.2007.11.008; J Thukral and M Ditmore; KM Blankenship and S Koester, 'Criminal Law, Policing Policy, and HIV Risk in Female Street Sex Workers and Injection Drug Users', Journal of Law, Medicine \& Ethics, vol. 30, no. 4, 2002, pp. 548-559, https://doi.org/10.1111/j.1748-720X.2002. tb00425.x. 
Our work in San Francisco immediately inspired the introduction of Assembly Bill 2243-Sex Worker Immunity (Laure Friedman, D-Glendale). This California bill allows sex workers who were engaged in an act of prostitution to come forward and file a complaint if they are the victim of a violent crime that occurred during the course of the act, or provide testimony as a witness to such a crime, without fear of being prosecuted for the act of prostitution. It created Evidence Code section 1162, which prohibits evidence of their, or their client's, criminal liability when they are the victim or witness of that crime. AB 2243 received unanimous bipartisan support, with law enforcement and prosecutors lending their support, and was signed by the Governor of California in June 2018. The law is not as strong as the Safety Policy and the SFPD Bulletin implemented in San Francisco, where people are guaranteed they will not be arrested. The bill did not address arrest due to concerns that it might not have enough support to pass if that language were included. In February 2019, California State Senator Scott Wiener introduced Senate Bill 233 that, if passed, will amend the penal code so that people will be granted immunity from arrest. ${ }^{28}$ If that bill does not pass, counties throughout California will want their police departments to issue their own policies, stating that people will not be arrested for prostitution or drug offenses if they come forward to report that they were the victim of, or witness to, a violent crime while selling sex.

Future work is needed to assess the implementation and impact of the 'Prioritizing Safety for Sex Workers Policy'. Anecdotally, the SFPD shared that, shortly after their Bulletin was issued, it was used to help support a sex worker who had been violently knifed by a client. ${ }^{29}$ That person did not want a bystander to call 911, and even when the bystander did call, the woman continued to refuse to share details with law enforcement officers for fear that her involvement in sex work would be used against her. It was only when an SFPD officer showed her a copy of the Bulletin that she felt supported enough to provide them with information that led to the arrest of the perpetrator. It is unknown whether the Safety Policy has had a negative impact on the communities of people it was created to better support.

\section{Conclusion}

The 'Prioritizing Safety for Sex Workers Policy' as enacted in San Francisco is a unique example of the way in which sex workers, people who have experienced trafficking, service providers, activists, women's rights policy makers, the Police Department, and the District Attorney's Office came together around a

28 Personal communication, S. Wiener.

29 Personal communication, A. Flores. 
common goal. The work recognises that the criminalisation of prostitution has created an environment where people feel they cannot file a report when they are the victim of, or witness to, a crime. This is echoed in the SFPD Bulletin, which states that, 'The criminalization of sex work is one of the primary barriers to reporting violence to law enforcement'. ${ }^{30}$ The hope is that this policy will reduce the harms experienced by people in the sex industry, send a clear message that violence against sex workers and people in the sex industry will be treated seriously under the law, and will serve as a model that can be used in other jurisdictions.

In comparison to other locations, San Francisco may be uniquely situated to do this type of collaborative work that is informed by the framework of sex workers' rights. Some of the reasons include the long history of sex worker activism, including sex workers and peer-based organisations being involved in local politics and partnering with municipal agencies. The relationships that have been built and maintained over the years have fostered a more collaborative and inclusive environment than seen almost anywhere else in the United States. It is still highly possible that the policy could be replicated elsewhere, especially if the focus is on addressing violence.

Acknowledgements: Thank you to Minouche Kandel and Saerom Choi who provided their feedback about this manuscript. Also, thank you to all those who worked for close to three years on getting the 'Prioritizing Safety for Sex Workers Policy' developed and enacted in San Francisco, CA. This includes representatives of Asian Pacific Islander Legal Outreach, Bay Area Sex Worker Advocacy Network, LYRIC, the Human Rights Commission, St. James Infirmary, Standing Against Global Exploitation, Red Light Legal, the San Francisco District Attorney's Office, the San Francisco Police Department, the San Francisco Public Defender's Office, San Francisco Women Against Rape, Sex Workers Outreach Project, and the US PROStitutes Collective.

Dr Alexandra Lutnick is an adjunct professor at the University of California, Berkeley. She is a social scientist whose research focuses on marginalised populations such as people who use drugs, those experiencing homelessness, people engaged in sex work, and those who are experiencing exploitation such as trafficking. Her work is grounded in harm reduction and strives to always engage community members in the process of knowledge production. alix provides consultation services to non-profit, government, and research organisations, and is a somatic yoga therapist. She is the author of Domestic Minor Sex Trafficking: Beyond victims and Villains (Columbia University Press, 2016).Email: alix.lutnick@gmail.com.

30 Scott. 